\title{
Soil moisture mapping over West Africa with a 30-min temporal resolution using AMSR-E observations and a satellite-based rainfall product
}

\author{
T. Pellarin ${ }^{1}$, T. Tran ${ }^{1}$, J.-M. Cohard ${ }^{1}$, S. Galle ${ }^{1}$, J.-P. Laurent ${ }^{1}$, P. de Rosnay ${ }^{2}$, and T. Vischel ${ }^{1}$ \\ ${ }^{1}$ LTHE, CNRS-INSU, IRD, Université de Grenoble, BP 53, 38041 Grenoble Cedex 9, France \\ ${ }^{2}$ European Centre for Medium-Range Weather Forecasts, Reading, UK
}

Received: 21 April 2009 - Published in Hydrol. Earth Syst. Sci. Discuss.: 3 June 2009

Revised: 16 September 2009 - Accepted: 21 September 2009 - Published: 15 October 2009

\begin{abstract}
An original and simple method to map surface soil moisture over large areas has been developed to obtain data with a high temporal and spatial resolution for the study of possible feedback mechanisms between soil moisture and convection in West Africa. A rainfall estimation product based on Meteosat geostationary satellite measurements is first used together with a simple Antecedent Precipitation Index (API) model to produce soil moisture maps at a spatial resolution of $10 \times 10 \mathrm{~km}^{2}$ and a temporal resolution of 30-min. However, given the uncertainty of the satellitebased rainfall estimation product, the resulting soil moisture maps are not sufficiently accurate. For this reason, a technique based on assimilating AMSR-E C-band measurements into a microwave emission model was developed in which the estimated rainfall rates between two successive AMSRE brightness temperature $(T B)$ measurements are adjusted by multiplying them by a factor between 0 and 7 that minimizes the difference between simulated and observed TBs. Groundbased soil moisture measurements obtained at three sites in Niger, Mali and Benin were used to assess the method which was found to improve the soil moisture estimates on all three sites.
\end{abstract}

\section{Introduction}

A number of recent papers have focused on the potential role of soil moisture in surface-precipitation feedback mechanisms. Many of these studies concern West Africa, a region with a strong coupling mechanism between soil moisture and precipitation in climate models, as shown by

Correspondence to: T. Pellarin (thierry.pellarin@hmg.inpg.fr)
Koster et al. (2004). The soil moisture-precipitation feedback can be either positive when the additional atmospheric humidity provided by a wet area tends to generate higher precipitation or negative when the soil moisture tends to reduce moist convection over wet areas. Taylor et al. (1997) found that rainfall patterns can persist over many storms in the Sahel, suggesting the presence of positive feedback. Similar findings have been found with model studies (Liu and Avissar 1999). On the other hand, some authors have found negative feedback, for instance Cheng and Cotton (2004), Taylor and Ellis (2006) and Cook et al. (2006).

A difficulty in studying soil moisture-precipitation feedback on the basis of observational data is the lack of sufficiently accurate soil moisture mapping at a suitable spatial and temporal scale. Today, no satellite sensor has optimal characteristics for soil moisture retrieval. The wavelengths as well as the spatial and temporal resolutions have not been specifically selected for continental studies (Prigent et al., 2005). However, many attempts on the determination of surface soil moisture have been achieved by using various satellite remote sensing data (see for instance Wen et al., 2003). In the near future, two proposed space missions will be exclusively devoted to the measurement of soil moisture from space: the SMOS mission (Kerr et al., 2001) and the SMAP mission (Entekhabi et al., 2007). Presently the AMSR-E sensor onboard the Aqua platform provides passive microwave measurements which are directly related to soil moisture over areas with no or little vegetation cover (Jackson et al., 2008). However, the temporal resolution of AMSR-E (ranging from $12 \mathrm{~h}$ to $36 \mathrm{~h}$ ) has been found to be insufficient to capture the rapid dynamics of surface soil moisture in West Africa (Pellarin et al., 2008). In Sahelian regions $\left(12^{\circ} \mathrm{N}-20^{\circ} \mathrm{N}\right)$, most rainfall events (80-90\%) are convective systems and are generally short-lived $(<10 \mathrm{~h})$ (Laurent et al., 1996; Mathon et al., 2002). In addition, warm atmospheric conditions in the Sahel

Published by Copernicus Publications on behalf of the European Geosciences Union. 
region produce high evaporation rates which rapidly dry the top centimetres of the soil that are observable by satellite microwave sensors.

In this paper, a method is proposed to obtain high resolution surface soil moisture estimates $\left(10 \times 10 \mathrm{~km}^{2}\right.$ spatial and 30-min temporal resolution) for statistical studies aimed at furthering our understanding of soil-atmosphere feedback mechanisms. Section 2 describes the methodology which uses two satellite-based measurements, a simple Antecedent Precipitation Index (API) model and a microwave emission model. The estimates are compared with soil moisture measurements acquired at ground level over a North-South gradient (Mali, Niger and Benin). Section 3 presents the results at the local and regional scale.

\section{Method}

The approach is based on the assimilation of AMSR-E microwave brightness temperatures $(T B)$ into a simple Antecedent Precipitation Index (API) model coupled with a microwave emission model. First, the API model uses a satellite-based rainfall estimation product (EPSAT-SG) as input to provide 2-D surface soil moisture maps for West Africa every 30-min. The microwave emission model produces the associated C-band $(6.9 \mathrm{GHz}) \mathrm{TBs}$. Then, an assimilation technique is used to modulate the satellite-based rainfall estimates in order to minimize the difference between simulated $T B$ s and the observed AMSR-E TBs. This original technique takes into account the uncertainty in the satellite-based rainfall estimates.

\subsection{EPSAT-SG satellite-based rainfall estimation product}

The EPSAT-SG rainfall product (Chopin et al., 2005) uses a neural network procedure to estimate rainfall on the basis of IR geostationary satellite data provided by METEOSAT 8 and low orbit satellite microwave data of the Tropical Rainfall Measurement Mission (TRMM) radar. The annual rainfall accumulation is forced to match the Global Precipitation Climatology Project (GPCP) rainfall product (Adler et al., 2003). A comparison of the EPSAT-SG rainfall product with ground-based rainfall measurements acquired over three sites in Niger, Mali and Benin is shown in Fig. 1. Note that EPSAT-SG tends to overestimate the total number of rainy days and underestimate the rainfall accumulation at the event timescale. The overestimation of the number of rainy days is frequently observed in satellite-based rainfall products based on statistical relationships between the top-cloud temperature value and precipitation rate measured at ground level. This is particularly true in the Sahel where strong evaporation of the rain can occur between the clouds and the ground. The total number of rainy days (from June to September 2006) based on ground-based measurements in Niger (Wankama

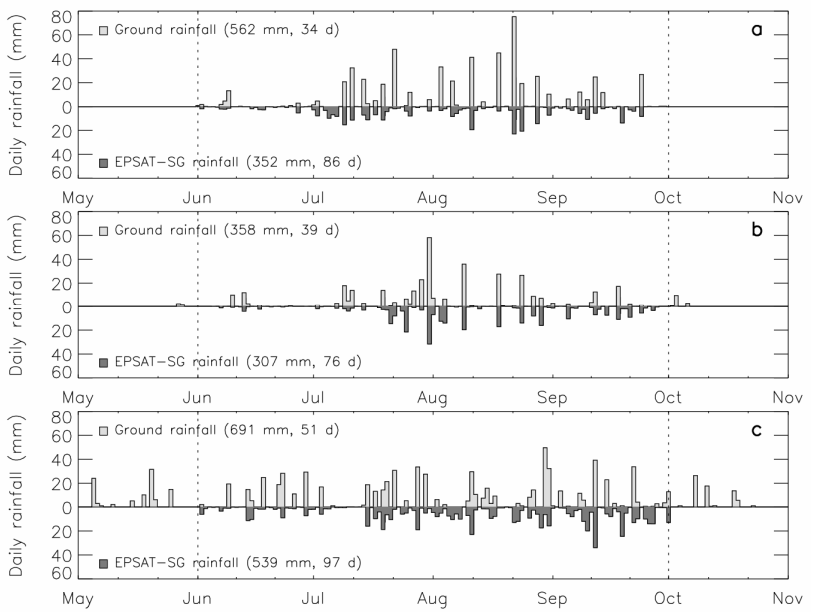

Fig. 1. Daily rainfall products (2006) over Niger (a), Mali (b) and Benin (c). Reference rainfalls (measured using raingauge stations) are plotted in light histograms and EPSAT-SG rainfalls are plotted in dark histograms. The total rainfall amount and the number of rainy days are indicated.

site) is 34 whereas EPSAT-SG indicates 86 days. In Mali (Agoufou site), the number of rainy days is 39 (ground level) and 76 (EPSAT-SG). In Benin (Nalohou site), the number of rainy days is 51 (ground level) and 97 days (EPSAT-SG). In addition, the total rain amount (from June to September) is underestimated by $37 \%, 14 \%$ and $22 \%$ for the Niger, Mali and Benin sites, respectively. On the other hand, note that each rainfall event detected by ground-based measurements is also detected by the satellite-based rainfall product.

\subsection{Ground-based soil moisture measurements}

In situ soil moisture measurements were obtained using CS616 sensors (Campbell Scientific Inc., Logan, Utah, USA) at three sites located in Niger at Wankama $\left(13.65^{\circ} \mathrm{N}\right.$, $\left.2.63^{\circ} \mathrm{E}\right)$, Mali at Agoufou $\left(15.35^{\circ} \mathrm{N}, 1.48^{\circ} \mathrm{W}\right)$ and Benin at Nalohou $\left(9.75^{\circ} \mathrm{N}, 1.61^{\circ} \mathrm{E}\right)$. Soil moisture sensors are located at $5 \mathrm{~cm}$ depth. Six soil moisture sensors were installed at the Wankama site, three at the Agoufou site and three at the Nalohou site. A detailed description of these measurements (and the calibration procedure) can be found in de Rosnay et al. (2009a) and Pellarin et al. (2009).

\subsection{API model}

A simple model is used to simulate soil water dynamics. It is based on the concept of the so-called API. As the API needs only precipitation data as model input, it has been widely used in rainfall-runoff applications to parameterize the soil moisture conditions in hydrological catchments (Sittner et al., 1969; Descroix et al., 2002). The API model can be 
expressed as:

$\mathrm{API}_{j}=\mathrm{API}_{j-1} e^{-30 / \delta}+P_{j}$

where $j$ is a daily time index, $P_{j}$ an estimate of the rainfall accumulation in mm over 30-min intervals, and $\delta$ a decreasing time parameter expressed in minutes. To match the API with observed volumetric soil moisture measurements $[v / v]$, Crow and Ryu (2009) proposed the following rescaling procedure:

$\theta_{j}=\left(\mathrm{API}_{j}-\mu^{\mathrm{API}}\right)\left(\sigma^{\theta} / \sigma^{\mathrm{API}}\right)+\mu^{\theta}$

The rescaling procedure ensures that the rescaled soil moisture possess a long-term mean $(\mu)$ and standard deviation $(\sigma)$ matching the observed mean soil moisture $\left(\mu^{\theta}\right)$ and standard deviation $\left(\sigma^{\theta}\right)$. However, the mean soil moisture $\left(\mu^{\theta}\right)$ and standard deviation $\left(\sigma^{\theta}\right)$ values are available only where in situ measurements are obtained. To produce 2-D soil moisture mapping over West Africa using the proposed approach, a spatial distribution of $\mu^{\theta}$ and $\sigma^{\theta}$ is required. To achieve this, 6 surface soil moisture time series measured in Mali (Bamba, Zaket, Ekia, Agoufou), Niger (Wankama) and Benin (Nalohou) were analyzed to find a statistical relationship between $\mu^{\mathrm{API}}$ and $\mu^{\theta}$ and a second relationship between $\sigma^{\mathrm{API}}$ and $\sigma^{\theta}$ as shown in Fig. 2. The two relationships can be written as:

$\mu^{\theta}=0.0062 \mu^{\mathrm{API}}$

$\sigma^{\theta}=0.0019 \sigma^{\mathrm{API}}+0.0211$

\subsection{C-band brightness temperatures simulations}

The C-MEB (C-band Microwave Emission of the Biosphere) model (Pellarin et al., 2006) was used to simulate brightness temperatures based on the 2-D soil moisture mapping obtained in the first step. In the C-MEB model, the polarized brightness temperature $\left(T B_{p}\right)$ is expressed as a function of the ground emissivity (ep) and the effective soil temperature ( $\left.T_{\text {eff }}\right)$ as $T B_{p}=e_{p} . T_{\text {eff. }}$. The ground emission is computed as $e_{p}=1-r_{p}$, where $r_{p}$ is the polarized microwave reflectivity which mainly depends on soil moisture and, to a small extent, soil density as well as textural and structural properties (Wigneron et al., 2007). Soil reflectivity is modelled using an approach based on the generalized semi-empirical formulation developed by Wang et al. (1983), involving three roughness parameters $\left(h_{\text {soil }}, q_{\text {soil }}\right.$ and $\left.N_{\text {soil }}\right)$ :

$r_{p}(\theta)=\left[\left(1-q_{\text {soil }}\right) r_{p}^{*}(\theta)+q_{\text {soil }} r_{q}^{*}(\theta)\right] \exp \left(-h_{\text {soil }} \cos ^{N_{\text {soil }}(\theta)}\right)$

where $\theta$ is the incidence angle and $r_{p}^{*}$ the soil reflectivity of a plane surface, which depends on the soil dielectric permittivity and the incidence angle. Wang et al. (1983) found that $N_{\text {soil }}=0$ gave results that were consistent with measurements at three frequencies $(1.4,5$, and $10.7 \mathrm{GHz})$. Concerning the soil dielectric permittivity, two studies devoted to West Africa have shown that the Mironov model (Mironov
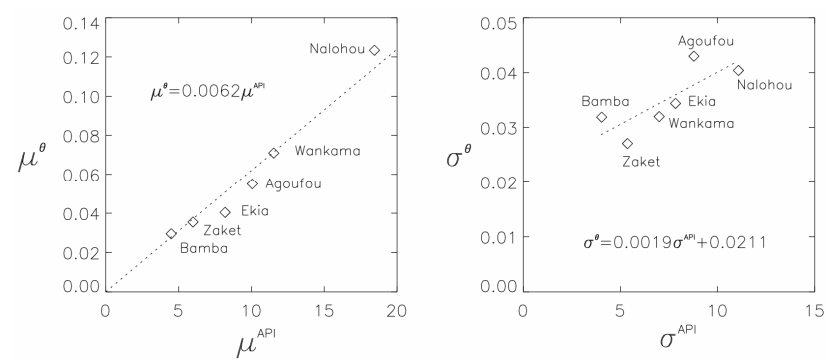

Fig. 2. (a) Statistical relationship between mean API (JuneSeptember) and mean surface soil moisture measured over six sites. (b) Same as (a) but concerning standard deviation.

et al., 2004) is suitably designed for African areas (Pellarin et al., 2009; de Rosnay et al., 2009b).

A simple estimation of the effective soil temperature was introduced by Wigneron et al. (2001) as a function of soil temperature at two depths and surface soil moisture:

$T_{\text {eff }}=T_{\text {deep }}+\left(w g / w_{0}\right)^{b w_{0}}\left(T_{\text {surf }}-T_{\text {deep }}\right)$

where $w g$ is the surface soil moisture, $w_{0}$ and $b w_{0}$ are semi-empirical parameters depending on the specific soil characteristics, and $T_{\text {surf }}$ and $T_{\text {deep }}$ are the soil temperatures at $1 \mathrm{~cm}$ and $50 \mathrm{~cm}$ depth, respectively. At the regional scale, surface soil temperatures were provided by the SEVIRI/MSG geostationary satellite and were processed by the LSA-SAF operational node at the Institute of Meteorology of Portugal. Under cloudy conditions, missing surface soil temperatures were replaced by modelled surface soil temperatures derived from the ISBA land surface model (Noilhan and Planton, 1989). Atmospheric fields required by ISBA were provided by the ALMIP Intercomparison Project (http://www.cnrm.meteo.fr/ amma-moana/amma_surf/almip/index.html and Boone et al., 2009). Similarly, deep soil temperature values were also derived from the ISBA land surface model. Note that the deep soil temperature had only a slight influence compared to that of soil emissivity.

When a vegetation layer is present on the soil surface, it attenuates the soil emission and adds its own contribution to the emitted radiation. At low frequencies, these effects can be well approximated by a simple semi-empirical model, referred to as the $\tau-\omega$ model. This model is based on the optical depth $\tau$ and the single scattering albedo $\omega$, which are used to represent, respectively, the vegetation attenuation properties and the scattering effects within the canopy layer (Mo et al., 1982). Based on the $\tau-\omega$ approach, several relationships have been proposed to compute the vegetation optical thickness. For West Africa, de Rosnay et al. (2009b) showed that the best parameterization was the Kirdyashev formulation (Kirdyashev et al., 1979). It expresses the vegetation optical thickness as a function of the wave number $\mathrm{k}$ (between $1 \mathrm{GHz}$ and $7.5 \mathrm{GHz}$ ), the dielectric constant of 
vegetation water $\varepsilon_{v w}^{\prime \prime}$ (imaginary part), $V W c$, incidence angle $\theta$, water density $\rho_{\text {water }}$ and a vegetation structure parameter $a_{\text {geo }}$ :

$\tau_{\text {veg, }}=a_{\text {geo }} k \frac{V W c}{\rho_{\text {water }}} \varepsilon_{v w}^{\prime \prime} \frac{1}{\cos \theta}$

The vegetation water content $(V W c)$ was derived from the leaf area index (LAI) provided by the ECOCLIMAP database (Masson et al., 2003).

\subsection{Assimilation of AMSR-E microwave measurements}

The assimilation technique proposed in this study assumes that the satellite-based rainfall rate estimates are possibly erroneous (as shown by daily rainfall amounts in Fig. 1) and can be improved by applying a simple multiplicative factor that minimizes the difference between observed (AMSRE) and simulated $T B$ s in terms of the root mean square error (RMSE). The sequential algorithm is based on two successive AMSR-E $T B$ measurements over a given pixel and computes eight soil moisture simulations using the following multiplicative factors: $0,0.25,0.5,1,2,3,5$ or 7 . The upper graph in Fig. 3 shows an example of the eight simulated surface soil moisture (SSM) time-series (solid lines) between two successive AMSR-E TB measurements and the corresponding adjusted rainfall rates (dotted lines). The lower graph presents the simulated $T B \mathrm{~s}$ associated with the eight soil moisture simulations. The two sets of curves correspond to horizontal (bottom) and vertical (top) polarization. The best solution is the factor that provides the best fit between simulated and observed $T B$ s, taking into account the horizontal and vertical polarization cases. In Fig. 3, the best solution is given by the multiplicative factor 2 .

\section{Results}

\subsection{API model at the local scale}

The API technique was assessed at the local scale using ground-based rainfall measurements and satellite-based rainfall estimates. A calibration procedure was used to find the best decreasing time parameter $\delta$ of Eq. (1) for the three sites of Wankama (Niger), Agoufou (Mali) and Nalohou (Benin). A value equal to 4 days $(\delta=5760 \mathrm{~min})$ was found to be relevant for the three sites. Comparisons were made using the mean value of all soil moisture measurements $(-5 \mathrm{~cm})$ located around Wankama (6 sensors), Agoufou (3 sensors) and Nalohou (3 sensors).

When ground-based rainfall measurements are used, the coefficients of determination $\left(R^{2}\right)$ are equal to $0.69,0.63$ and 0.50 at the Wankama, Agoufou and Nalohou sites, respectively. The total number of rainy days from 1 June to 30 September is mentioned in Fig. 1 (a rainy day corresponds to a 24-h period during which a rain event occurs).
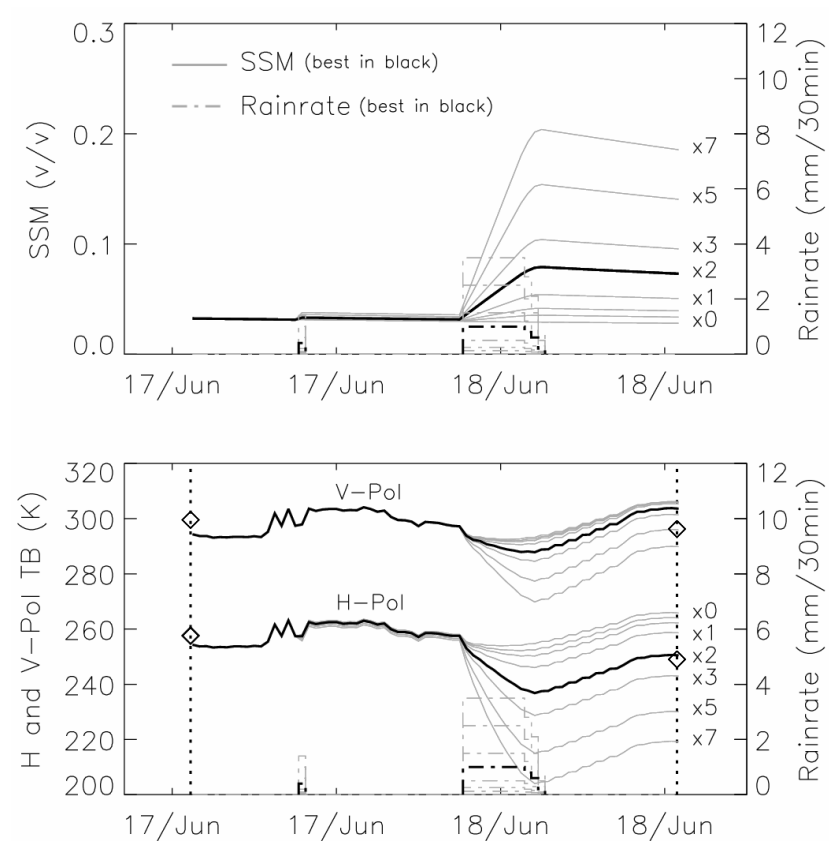

Fig. 3. Illustration of the methodology based on the selection of the rainfall rate that minimizes the difference between AMSR-E TB observations (diamonds in the two curves of the lower graph) and simulated $T B$. Here, the best $T B$ simulation (curves in bold) is obtained using a multiplicative factor of 2 on the rainfall rate (Niger site).

When satellite-based rainfall estimates (EPSAT-SG) are used, the agreement $\left(R^{2}\right)$ between observed and estimated soil moisture decreases from 0.69 to 0.28 at Wankama, from 0.63 to 0.36 at Agoufou, and from 0.50 to 0.46 at Nalohou. These lower scores are mainly due to the strong underestimation of rainfall amounts at the beginning of the rainy season (June to mid-July) and the overestimation of the number of rainy days. False rain events are indicated at the Wankama site at the beginning of July and at the end of September. Despite that, due to the normalization procedure presented in Sect. 2.3, the methodology provides surface soil moisture estimates with a low bias $(<1.6 \%$ vol. $)$ and relatively low $\operatorname{RMSE}(<3.7 \%$ vol.).

\subsection{Microwave brightness temperatures at the regional scale}

Based on the EPAST-SG rainfall product $\left(10 \times 10 \mathrm{~km}^{2}, 30\right.$ min), soil moisture maps at the same spatial and temporal resolution were constructed using Eqs. (1) to (4) at the regional scale. To compute microwave brightness temperatures, the ECOCLIMAP database was used to differentiate three types of land cover (bare soil, forest and herbaceous vegetation) as shown in Fig. 5. The vegetation water content $(V W c)$ values were fixed at $4 \mathrm{~kg} / \mathrm{m}^{2}$ for forest and $0.5 \times$ LAI for herbaceous vegetation (Pellarin et al., 2003) 

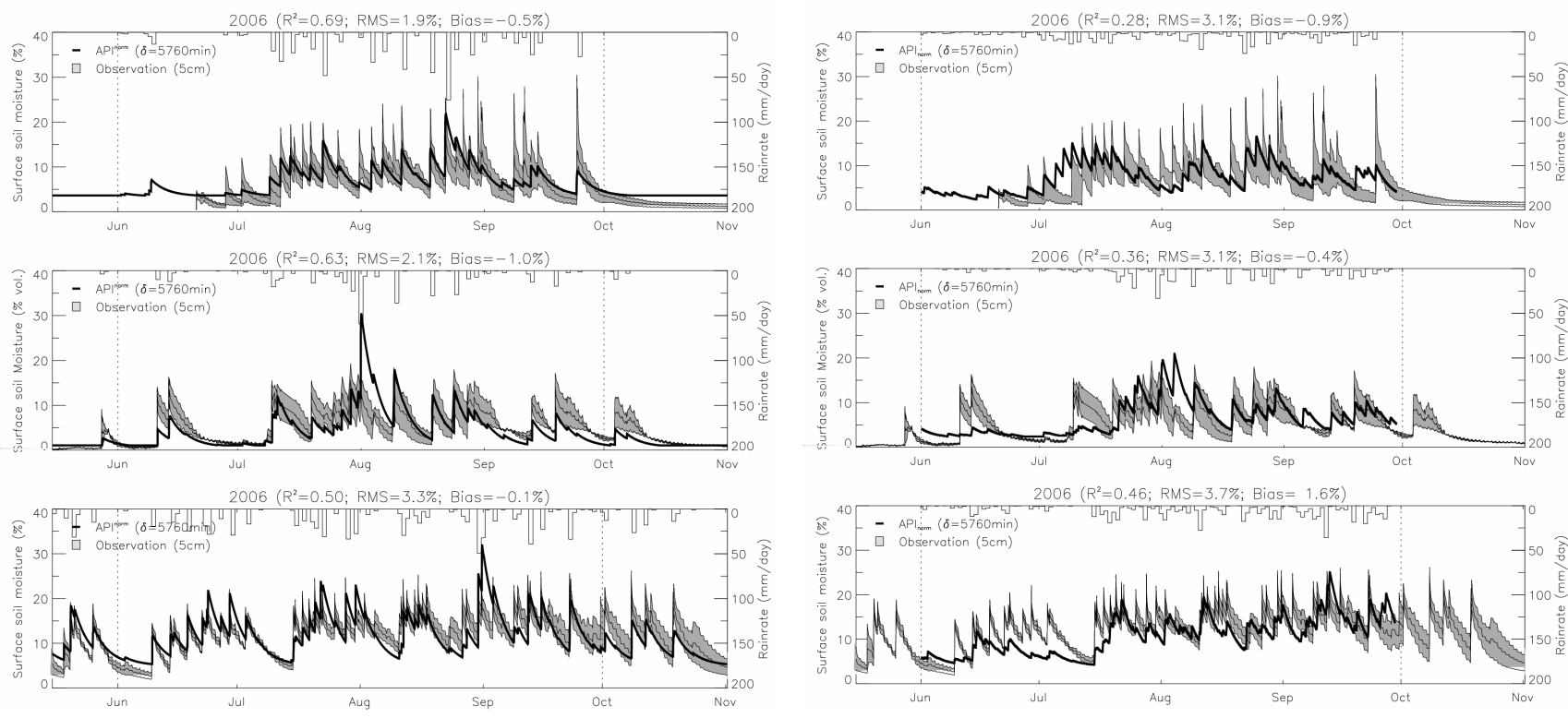

Fig. 4. Observed (grey areas) and estimated surface soil moisture (black thick lines) during 2006 over three sites (Wankama, Agoufou and Nalohou) using API model and ground-based rainfall measurements (left 3 graphs) and satellite-based rainfall estimates (right 3 graphs).
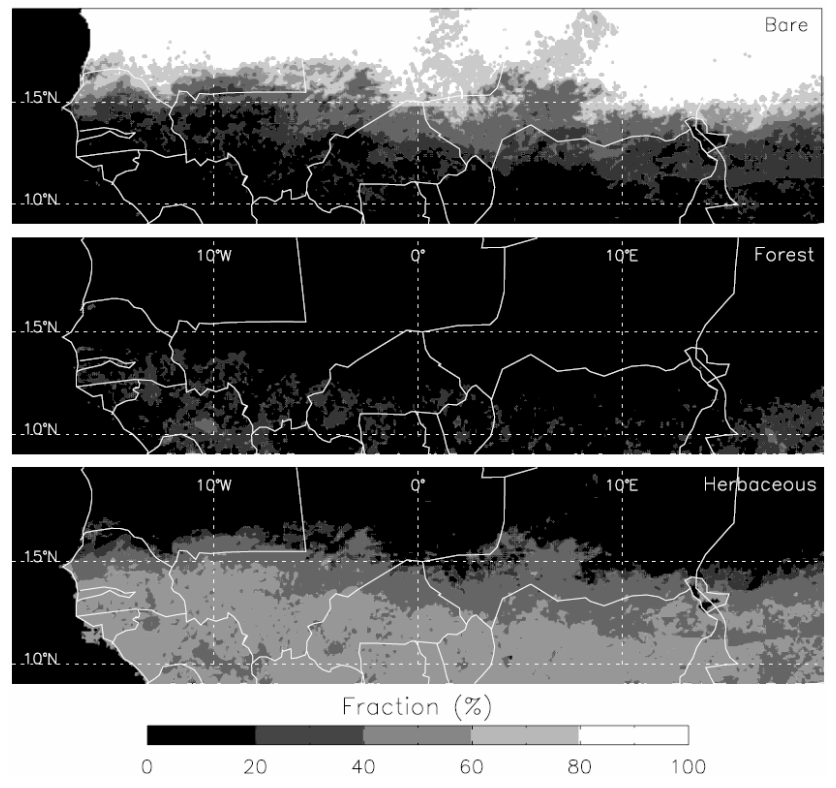

Fig. 5. Soil fraction used for the microwave $T B$ simulation: bare soil fraction (top), forest fraction (middle) and herbaceous vegetation fraction (bottom).

with LAI derived from the ECOCLIMAP database. The $a_{\text {geo }}$ parameter value was fixed at 0.66 for forest and 0.33 for herbaceous vegetation (Kirdyashev et al., 1979).

The C-MEB model was calibrated to account for the spatial variability of roughness parameters in West Africa, which can play a significant role in soil microwave emission. Simulations were run using the C-MEB model with a large range of values for the four soil parameters ( $h_{\text {soil }}, q_{\text {soil }}, w_{0}$ and $\left.b w_{0}\right)$ and the EPSAT-SG rainfall product from June to September 2006. Based on the root mean square errors (RMSE) between simulated and AMSR-E observed TBs, the two parameters related to the effective temperature have a minor impact on $T B$ simulations. On the other hand, $h_{\text {soil }}$ and $q_{\text {soil }}$ parameters have a strong impact on $T B$ simulations and a large dispersion of the two roughness parameters was found, as shown in Fig. 6. The $h_{\text {soil }}$ and $q_{\text {soil }}$ maps reflect the topography (mountains of Airr, Tibesti, and south of the Hoggar). In the south of the domain, covered with vegetation, the dispersion of the hsoil and qsoil values is due to a mixed contribution of soil roughness, topography and vegetation.

An example of estimated surface soil moisture mapping and associated simulated brightness temperatures $(\mathrm{H}-$ polarization) is shown in Fig. 7 for 9 August 2006 at 01:30 a.m. The same figure shows the corresponding AMSR-E measurements (descending track, 9 August 2006 at 01:38 a.m.). General agreement can be observed between the simulated and observed $T B$ s due to a significant rain system that wet a large part of the Sahel, from the south of the Aïr Mountains (Niger) to southern Mali, extending through northern Mali. However, a detailed analysis of the simulated $T B$ signature reveals some significant differences with respect to the AMSR-E signature. For instance, soil moisture simulations (and associated $T B \mathrm{~s}$ ) display a wet area in northwestern Mali (centred at $\sim 4^{\circ} \mathrm{E}, 19^{\circ} \mathrm{N}$ ) whereas no signature of a wet area can be observed in the AMSR-E measurements. Figure $7 \mathrm{~b}$ also shows the vegetation optical thickness calculated using Eq. (7), which describes regions with a high degree of vegetation cover. 


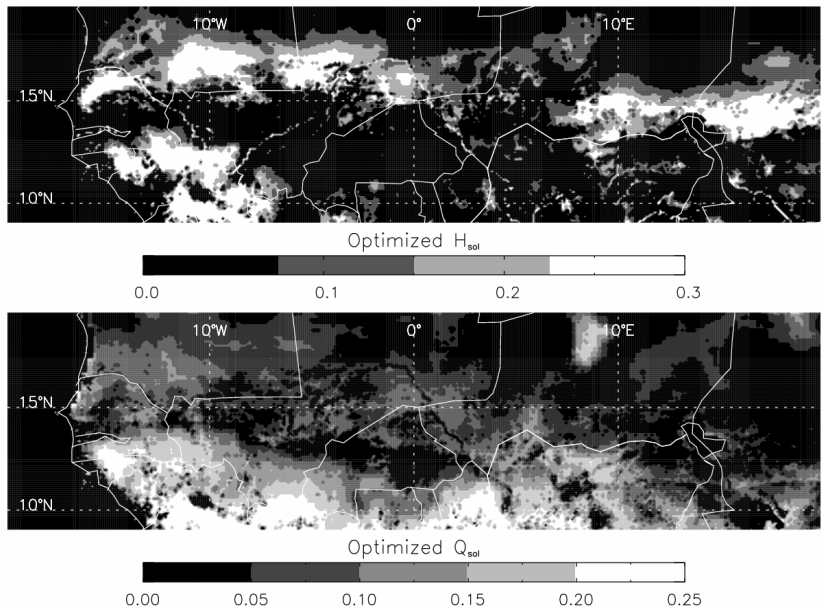

Fig. 6. Soil roughness parameter (hsoil and qsoil) mapping obtained by a calibration procedure based on AMSR-E $T B$ measurements and the C-MEB model.

\subsection{AMSR-E assimilation}

In the assimilation technique used in this study, the EPSATSG rainfall rate estimates between two successive AMSR-E brightness temperature $(T B)$ measurements are adjusted by multiplying them by a factor between 0 to 7 that minimizes the difference between simulated and observed $T B$ s.

\subsubsection{Results of the assimilation technique at the local scale}

The initial results of the assimilation technique generated some significant overestimations of the soil moisture which in some cases lasted a long time after an important rainfall event. In order to avoid this problem, a second value of the $\delta$ decreasing time parameter was introduced to allow a rapid decrease of the soil moisture. The rapid decrease ( $\delta=2880 \mathrm{~min}$, i.e. 2 days) of the soil moisture is proposed only in cases where no rain event occurs between two AMSR-E measurements. This is to avoid ambiguous results provided by either a significant rainfall associated with a rapid decrease of soil moisture or a small rainfall associated with a slow decrease of soil moisture. Results at the local scale are shown in Fig. 8 and statistical scores $\left(R^{2}\right.$, RMSE and bias) are presented in Table 1.

Note that the assimilation technique significantly increases the agreement between observed and simulated soil moisture at the Wankama site. The coefficient of determination $\left(R^{2}\right)$ increases from 0.28 to 0.59 . In addition, the soil moisture variations that were limited to the range 0.03 to $0.15 \mathrm{~m}^{3} \mathrm{~m}^{-3}$ before assimilation are now more in agreement with the ground measurements $\left(0.01\right.$ to $\left.0.28 \mathrm{~m}^{3} \mathrm{~m}^{-3}\right)$. Finally, the greatest improvement can be observed at the beginning of
Table 1. Statistical scores of the soil moisture estimates for the three local scale sites. Simulations were done using (a) groundbased rainfall estimates, (b) EPSAT-SG rainfall estimates and (c) EPSAT-SG rainfall estimates with assimilation technique. Column (d) corresponds to the assimilation technique performed with the $\tau_{\max }$ threshold.

\begin{tabular}{llrrrr}
\hline \multirow{5}{*}{ Wankama } & & $\begin{array}{r}\text { Ground rainfall } \\
\text { (a) }\end{array}$ & $\begin{array}{r}\text { EPSAT-SG } \\
\text { rainfall (b) }\end{array}$ & $\begin{array}{r}\text { Assimilation } \\
\text { (c) }\end{array}$ & $\begin{array}{r}\text { Assimilation } \\
\text { (d) }\end{array}$ \\
\hline \multirow{5}{*}{ Agoufou } & $R^{2}$ & 0.69 & 0.28 & 0.59 & \\
& RMSE (\%vol.) & 1.9 & 3.1 & 2.9 & unchanged \\
& Bias (\% vol.) & -0.5 & -0.9 & -1.3 & \\
& Rainy days & 34 & 86 & 63 & \\
& $R^{2}$ & 0.63 & 0.36 & 0.38 & \\
& RMSE (\%vol.) & 2.1 & 3.1 & 3.1 & unchanged \\
& Bias (\% vol.) & -1.0 & -0.4 & -0.7 & \\
& Rainy days & 39 & 76 & 54 & \\
\hline \multirow{5}{*}{ Nalohou } & $R^{2}$ & 0.50 & 0.46 & 0.35 & 0.51 \\
& RMSE (\%vol.) & 3.3 & 3.7 & 3.7 & 3.1 \\
& Bias (\% vol.) & -0.1 & 1.6 & 1.0 & 0.3 \\
& Rainy days & 51 & 97 & 84 & 86 \\
\hline
\end{tabular}

July and end of September where most of the overestimated EPSAT-SG rainfalls were corrected by the assimilation technique, as can be seen by comparing Figs. 4 and 8 .

At the Agoufou site, the improvement is weaker. $R^{2}$ increases from 0.36 to 0.38 . The soil moisture variations at the beginning and end of the rainy season are in better agreement with observations. On the other hand, a minor rainfall event (5 September 2006, $2 \mathrm{~mm}$ measured on the ground) is overestimated by the assimilation technique. This behaviour might be explained by the different spatial scales used in the comparison and could represent a limitation of the methodology. The observations are point measurements obtained from soil moisture probes whereas the assimilation technique is based on the AMSR-E measurements which have a resolution of $25 \times 20 \mathrm{~km}^{2}$. In some cases, in particular at the periphery of large rainfall systems, the point measurement may not be representative of the surrounding $25 \times 20 \mathrm{~km}^{2}$ area, leading to major differences between the observed soil moisture values and those determined by the assimilation technique.

Another limitation of the methodology was found at the Nalohou site and is related to the attenuation of microwave emission by vegetation. As the vegetation cover increases (at the end of the rainy season), the sensitivity to soil moisture decreases. A sensibility test was conducted at the Nalohou site in Benin to define the vegetation optical depth threshold $\left(\tau_{\max }\right)$ for which the surface soil moisture becomes negligible. A value of $\tau_{\max }$ equal to 2.4 was found and corresponds to the 20 August value at the Nalohou site. Note that $\tau_{\max }$ is equal to $\tau_{\text {nadir }} \cos \theta$, where $\theta$ is the satellite incidence angle (55 for AMSR-E), which corresponds to $\tau$ nadir equal to 1.38. The assimilation technique was modified so that the assimilation is stopped when the optical thickness of the vegetation exceeds 2.4 . In such cases, the original rainfall rate is used and no modification of the rainfall rate is allowed. Results of the second assimilation technique are shown in 

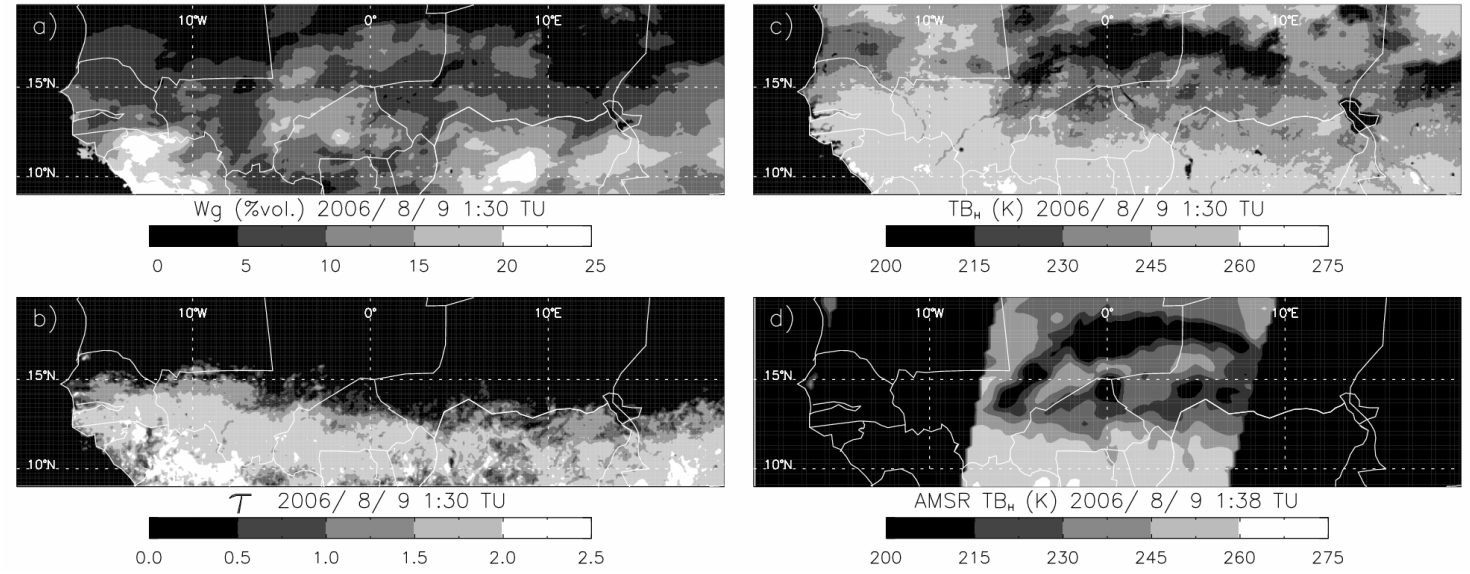

Fig. 7. (a) Surface soil moisture mapping obtained using the API model and the EPSAT-SG rainfall estimation product. (b) The vegetation Cband optical depth obtained using Eq. (7) and VWc provided by the ECOCLIMAP database. For the same date (9 August 2006, 01:38 a.m.), the two graphs on the right present (c) the simulated $T B$ and (d) the corresponding AMSR-E horizontal polarization $T B$ s.
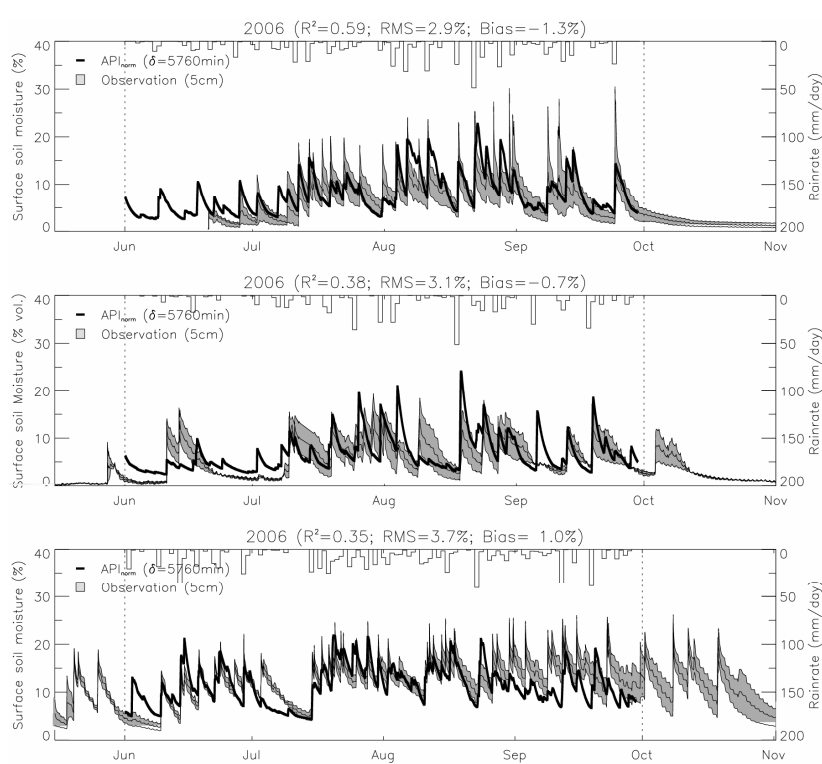

Fig. 8. Observed (grey area) and estimated surface soil moisture (2006) over three sites (Wankama, Agoufou and Nalohou) after assimilation of the AMSR-E TB measurements. Histograms present the rainfall amounts obtained after applying the assimilation technique.

Fig. 9 and the corresponding scores are presented in Table 1. Note that the second assimilation technique has no effect on the Wankama and Agoufou sites since the optical thickness of the vegetation never exceeds 2.4 at these locations. Using the optical thickness threshold, $R^{2}$ increases from 0.35 to 0.51 at the Nalohou site.

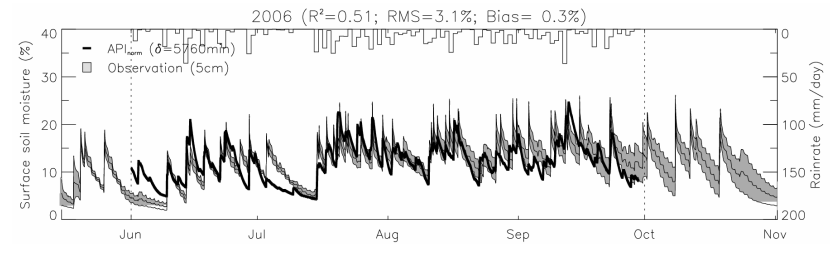

Fig. 9. Result of the assimilation technique over the Nalohou site using the $\tau_{\max }$ threshold. When the vegetation optical thickness at $55^{\circ}$ incidence angle exceeds 2.4 , no modification of the rainfall rate is allowed.

\subsubsection{Results of the assimilation technique at the regional scale}

The assimilation technique was applied at the regional scale. Surface soil moisture mapping and associated simulated brightness temperatures (H-polarization) for 9 August 2006 at 01:30 a.m. are presented in Fig. 10. Also shown in Fig. 10b is the vegetation optical thickness calculated using Eq. (7) and the observed AMSR-E TB (d). First, note the excellent agreement between observed and simulated $T B \mathrm{~s}$. This is not surprising since the assimilation technique selects the $T B$ that is closest to the observed AMSR-E TB. The pattern of the wet area is now close to the observed pattern and wet areas in the east of the domain and in northern Mali have been eliminated. Consequently, the soil moisture mapping (10a) is significantly different from the original one in Fig. 7a. As in Fig. 7, the vegetation optical thickness is shown as well as the AMSR-E $T B \mathrm{~h}$ measurements. 

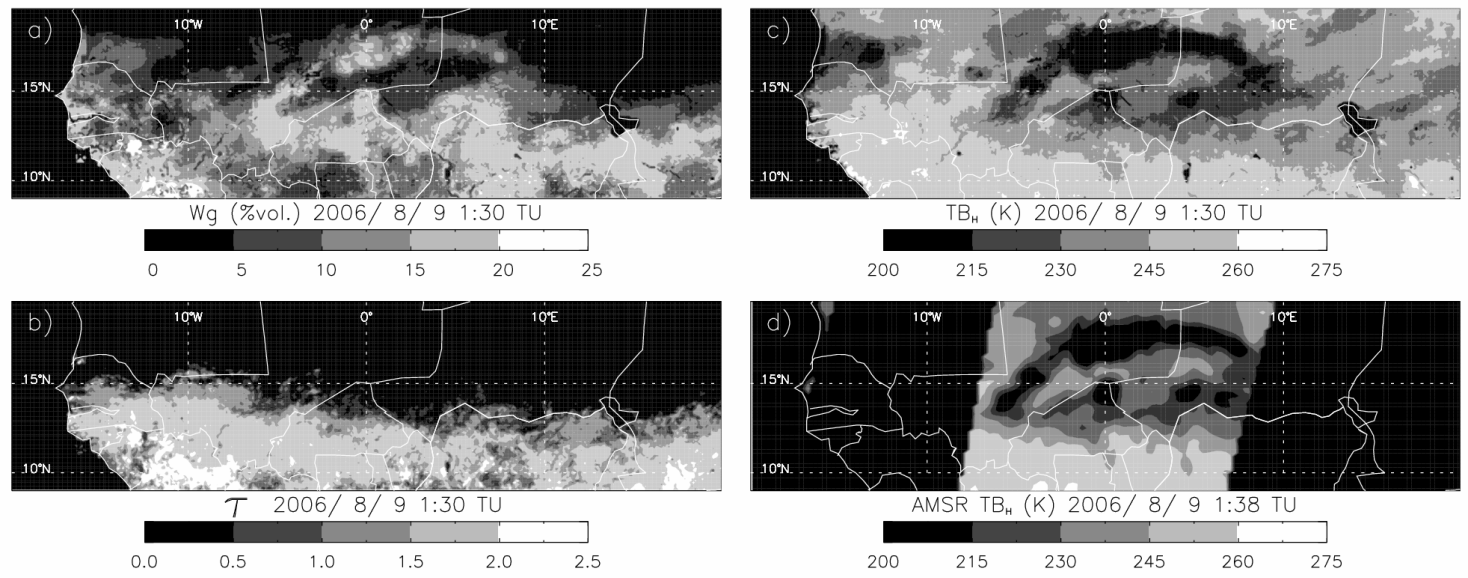

Fig. 10. Same as Fig. 7 but after the assimilation procedure.

\subsubsection{Rainfall estimates provided by the assimilation technique}

The aim of this study is to provide accurate surface soil moisture mapping with a high temporal and spatial resolution over West Africa. To achieve this, the proposed method modulates a rainfall estimation product in order to make observed and simulated soil microwave emissions match. After assimilation, new rainfall estimates are obtained and are compared to ground-based rainfall measurements in Fig. 11.

At the Wankama site, the estimated total rainfall accumulation was increased from $352 \mathrm{~mm}$ (EPAST-SG) to $538 \mathrm{~mm}$ after assimilation, approaching the total rainfall accumulation from ground-based measurements $(562 \mathrm{~mm})$. In addition, there were 86 rainy days (d) in the EPSAT-SG product and the new number of rainy days was decreased to 63, closer to the number of rainy days from ground-based measurements (34).

At the Agoufou site, the estimated total rainfall accumulation was increased from $307 \mathrm{~mm}$ (EPAST-SG) to $480 \mathrm{~mm}$ after assimilation whereas the total rainfall accumulation from ground-based measurements was $358 \mathrm{~mm}$. Although the number of rainy days was decreased from 76 to 54 (39 on the ground), the total rainfall accumulation is strongly overestimated by the methodology.

At the Nalohou site, the estimated total rainfall accumulation as well as the number of rainy days was improved by the assimilation technique, as shown in Fig. 11c.

The strong overestimation of the rainfall amount at the Agoufou site was investigated and was found to be related to the time between two successive AMSR-E measurements which can be up to $36 \mathrm{~h}$. Thus, a rainfall event that occurs 24 to $36 \mathrm{~h}$ before a given AMSR-E measurement has a very weak signature or even no signature at all, as already observed by Pellarin et al. (2008). Consequently, the amount of rainfall has almost no influence on the soil emission $36 \mathrm{~h}$ later. Thus, the assimilation technique may select a large

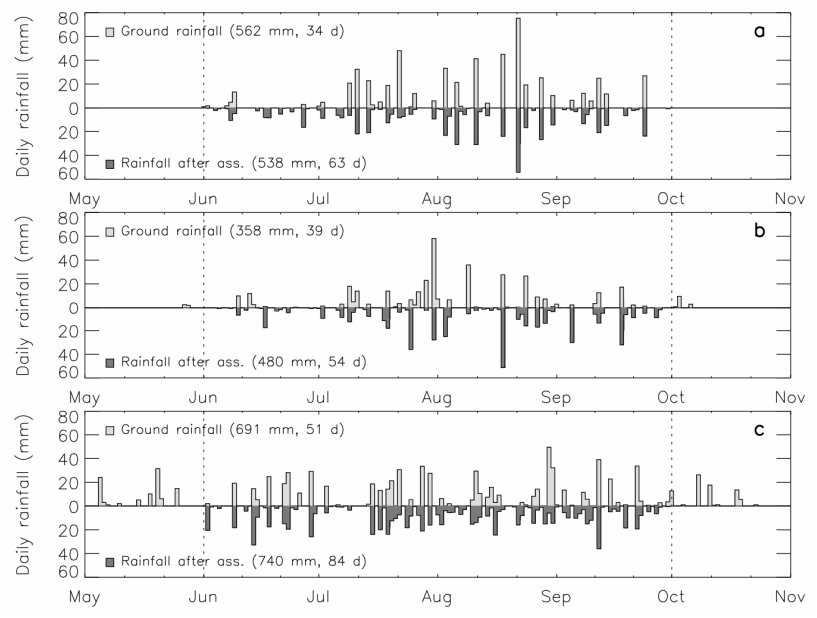

Fig. 11. Daily rainfall products (2006) over (a) Niger, (b) Mali and (c) Benin. Reference rainfalls (measured using raingauge stations) are plotted in light histograms and dark histograms represent the rainfall product provided by the assimilation technique. The total rainfall amount and the number of rainy days are indicated.

multiplicative factor that can be erroneous. This is particularly true in Mali where atmospheric conditions can produce high evaporation rates after a rainy event.

\section{Conclusions}

This paper presents an original and simple method to map surface soil moisture with a high temporal and spatial resolution over large areas using a satellite-based rainfall estimation product and soil C-band microwave emissions. The method accounts for rainfall uncertainties associated with all satellite-based rainfall products by assimilating AMSR-E Cband measurements into an Antecedent Precipitation Index model coupled with a microwave emission model. 
The method was assessed at the local scale using ground soil moisture measurements. An initial limitation of the method was found to be related to the strong C-band attenuation of the vegetation cover over forested areas (south of the domain). When the optical thickness of the vegetation exceeded 2.4 (i.e. 1.38 at nadir), the assimilation technique was found to be ineffective. A second limitation was related to the possible underestimation or overestimation of a rain event by the assimilation technique due to the different spatial resolution of the precipitation product and the microwave emission measurements. Further work is required to improve the method so that it can provide simultaneous soil moisture and rainfall maps. The first limitation was solved by placing a threshold on the optical thickness of the vegetation, improving soil moisture retrieval at the Nalohou site in Benin. No modification has been proposed to solve the second limitation which concerns only a few days, mainly in Mali.

In term of perspectives, these soil moisture maps will be used to study the potential role of soil moisture in the initiation of convection in the Sahel. In addition, within the framework of the SMOS mission, these maps will be helpful in the calibration/validation procedure scheduled for summer 2010 in West Africa. Plans have been made to improve the method by correcting the rainfall estimates using satellitebased soil moisture measurements as suggested by Crow and Bolten (2007) and Crow et al. (2009).

Acknowledgements. This work is part of the AMMA program. Based on a French initiative, the AMMA program has been set up by an international scientific group and is currently funded by a large number of agencies, especially from France, the UK, the US and Africa. It has benefited from a major financial contribution from the European Community's Sixth Framework Research Programme. Detailed information on scientific coordination and funding is available on the AMMA International web site http://www.amma-international.org.

The authors wish to thank the National Snow and Ice Data Center (NSIDC) for providing AMSR-E/Aqua daily L3 surface soil moisture data (AMSR-E/Aqua daily L3 surface soil moisture, interpretive parms, and QC EASE-Grids (Njoku, E), January to December 2006).

Edited by: J. Liu

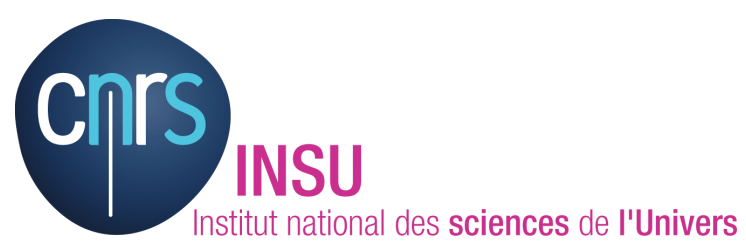

The publication of this article is financed by CNRS-INSU.

\section{References}

Adler, R. F., Huffman, G. J., Chang, A., Ferraro, R., Xie, P. P., Janowiak, J., Rudolf, B., Schneider, U., Curtis, S., Bolvin, D., Gruber, A., Susskind, J., Arkin, P., and Nelkin, E.: The version2 global precipitation climatology project (GPCP) monthly precipitation analysis (1979-present), J. Hydrometeorol., 4, 11471167, 2003.

Boone A., de Rosnay, P., Balsamo, G., Beljaars, A., Chopin, F., Decharme, B., Delire, C., Ducharne, A., Gascoin, S., Guichard, F., Gusev, Y., Harris, P., Jarlan, L., Kergoat, L., Mougin, E., Nasonova, O., Norgaard, A., Orgeval, T., Ottlé, C., PoccardLeclercq, I., Polcher, J., Sandholt, I., Saux-Picart, S., C. Taylor, M., and Xue, Y.: The AMMA Land Surface Model Intercomparison Project (ALMIP), Bull. American Meteor. Soc., doi:10.1175/2009BAMS2786.1, in press, 2008.

Cheng, W. Y .Y. and Cotton, W. R.: Sensitivity of a cloud-resolving simulation of the genesis of a mesoscale convective system to horizontal heterogeneities in soil moisture initialization, J. Hydrometeorol., 5, 934-958, 2004.

Chopin F., Bergès J.C., Desbois M., Jobard I., and Lebel, T.: Satellite Rainfall Probability and Estimation. Application to the West Africa During the 2004 Rainy Season, American Geosciences Union, 2005 Joint Assembly New Orleans, USA 23-27 May, 2005.

Cook, B. I., Bonan, G. B., and Levis, S.: Soil moisture feedbacks to precipitation in southern Africa, J. Climate, 19, 4198-4206, 2006.

Crow, W. T. and Bolten, J. D.: Estimating precipitation errors using spaceborne surface soil moisture retrievals, Geophys. Res. Lett., 34, L08403, 2007.

Crow, W. T., Huffman, G. J., Bindlish, R., and Jackson, T. J.: Improving Satellite-Based Rainfall Accumulation Estimates Using Spaceborne Surface Soil Moisture Retrievals, J. Hydrometeorol., 10, 199-212, 2009.

Crow, W. T. and Ryu, D.: A new data assimilation approach for improving runoff prediction using remotely-sensed soil moisture retrievals, Hydrol. Earth Syst. Sc., 13, 1-16, 2009.

Descroix L., Nouvelot J., and Vauclin M.: Evaluation of an antecedent precipitation index to model runoff yield in the western Sierra Madre (north-west Mexico), J. Hydrol., 263(1-4), 114 130, 2002.

Entekhabi, D., Njoku, E. O’Neill, P. Spencer, M., Jackson, T., Entin, J., Im, E., and Kellogg, K. : The Soil Moisture Active/Passive Mission (SMAP), Geoscience and Remote Sensing Symposium, IGARSS 2008(3), III 1-3, 2008

Jackson, T. J., Moran, M. S., and O’Neill, P. E.: Introduction to Soil Moisture Experiments 2004 (SMEX04) Special Issue, Remote Sens. Environ., 112, 301-303, 2008.

Kerr, Y. H., Waldteufel, P., Wigneron, J. P., Martinuzzi, J. M., Font, J., and Berger, M.: Soil moisture retrieval from space: The Soil Moisture and Ocean Salinity (SMOS) mission, IEEE T. Geosci. Remote, 39, 1729-1735, 2001.

Kirdyashev, K. P., Chukhlantsev, A. A., and Shutko, A. M.: Microwave radiation of grounds with vegetative cover, Radiotekh. Elektron., 24, 256-264, 1979.

Koster, R. D., Dirmeyer, P. A., Guo, Z. C., Bonan, G., Chan, E., Cox, P., Gordon, C. T., Kanae, S., Kowalczyk, E., Lawrence, D., Liu, P., Lu, C. H., Malyshev, S., McAvaney, B., Mitchell, K., Mocko, D., Oki, T., Oleson, K., Pitman, A., Sud, Y. C., Taylor, 
C. M., Verseghy, D., Vasic, R., Xue, Y. K., Yamada, T., anad Team, G.: Regions of strong coupling between soil moisture and precipitation, Science, 305, 1138-1140, 2004.

Laurent, H., Jobard, I., and Toma, A.: Validation of satellite and ground-based estimates of precipitation over the Sahel, Atmos. Res., (47-48), 651-670, 1998.

Liu, Y. Q. and Avissar, R.: A study of persistence in the landatmosphere system using a general circulation model and observations, J. Climate, 12, 2139-2153, 1999.

Masson, V., Champeaux, J. L., Chauvin, F., Meriguet, C., and Lacaze, R.: A global database of land surface parameters at 1-km resolution in meteorological and climate models, J. Climate, 16, 1261-1282, 2003.

Mathon, V., Laurent, H., and Lebel, T.: Mesoscale convective system rainfall in the Sahel, J. Appl. Meteorol., 41, 1081-1092, 2002.

Mironov, V. L., Dobson, M. C., Kaupp, V. H., Komarov, S. A., and Kleshchenko, V. N.: Generalized refractive mixing dielectric model for moist soils, IEEE T. Geosci. Remote., 42, 773-785, 2004.

Mo, T., Choudhury, B. J., Schmugge, T. J., Wang, J. R., and Jackson, T. J. A model for microwave emission from vegetationcovered fields, J. Geophys. Res.-Oc. Atm., 87, 1229-1237, 1982.

Noilhan, J. and Planton, S.: A simple parameterization of land surface processes for meteorological models, Mon. Weather Rev., 117, 536-549, 1989.

Pellarin, T., Ali, A., Chopin, F., Jobard, I., and Berges, J. C.: Using spaceborne surface soil moisture to constrain satellite precipitation estimates over West Africa, Geophys. Res. Lett., 35, L02813, 2008.

Pellarin, T., Calvet, J. C., and Wigneron, J. P.: Surface soil moisture retrieval from L-band radiometry: A global regression study, IEEE T. Geosci. Remote, 41, 2037-2051, 2003.

Pellarin, T., Kerr, Y. H., and Wigneron, J. P.: Global simulation of brightness temperatures at 6.6 and $10.7 \mathrm{GHz}$ over land based on SMMR data set analysis, IEEE T. Geosci. Remote, 44, 24922505, 2006.

Pellarin, T., Laurent, J.-P., Cappelaere, B., Decharme, B., Descroix, L., Ramier, D.: Hydrological modelling and associated microwave emission of a semi-arid region in South-western Niger, J. Hydrol., 375(1-2), 262-272, doi:10.1016/j.jhydrol.2008.12.003, 2009.
Prigent, C., Aires, F., Rossow, W. B., and Robock, A.: Sensitivity of satellite microwave and infrared observations to soil moisture at a global scale: Relationship of satellite observations to in situ soil moisture measurements, J. Geophys. Res.-Atmos., 110, D07110, 2005.

de Rosnay, P., Gruhier, C., Timouk, F., Baup, F., Mougin, E., Hiernaux, P., Kergoat, L., and LeDantec, V.: Multi-scale soil moisture measurements at the Gourma meso-scale site in Mali, J. Hydrol., 375(1-2), 241-252, doi:10.1016/j.jhydrol.2009.01.015, 2009a.

de Rosnay P., M. Drusch, A. Boone, G. Balsamo, B. Decharme, P. Harris, Y. Kerr, T. Pellarin, J. Polcher and J.-P. Wigneron, "The AMMA Land Surface Model Intercomparison Experiment coupled to the Community Microwave Emission Model: ALMIP-MEM", J. Geophys. Res., 114, D05108, doi:10.1029/2008JD010724, 2009b.

Sittner, W., Schauss, C., and Monro, J.: Continuous hydrograph synthesis with an API-type hydrologic model, Water Resour. Res., 5(5), 1007-1022, 1969.

Taylor, C. M. and Ellis, R. J.: Satellite detection of soil moisture impacts on convection at the mesoscale, Geophys. Res. Lett., 33, L03404, 2006.

Taylor, C. M., Said, F., and Lebel, T.: Interactions between the land surface and mesoscale rainfall variability during HAPEX-Sahel, Mon. Weather Rev., 125, 2211-2227, 1997.

Wang, J. R., Oneill, P. E., Jackson, T. J., and Engman, E. T.: Multifrequency measurements of the effects of soil-moisture, soil texture, and surface-roughness, IEEE T. Geosci. Remote, 21, 44-51, 1983.

Wigneron, J. P., Kerr, Y., Waldteufel, P., Saleh, K., Escorihuela, M. J., Richaume, P., Ferrazzoli, P., de Rosnay, P., Gurney, R., Calvet, J. C., Grant, J. P., Guglielmetti, M., Hornbuckle, B., Matzler, C., Pellarin, T., and Schwank, M.: L-band Microwave Emission of the Biosphere (L-MEB) Model: Description and calibration against experimental data sets over crop fields, Remote Sens. Environ., 107, 639-655, 2007.

Wigneron, J. P., Laguerre, L., and Kerr, Y. H.: A simple parameterization of the L-band microwave emission from rough agricultural soils, IEEE T. Geosci. Remote., 39, 1697-1707, 2001.

Wen, J., Su, Z., and Ma, Y.: Determination of land surface temperature and soil moisture from Tropical Rainfall Measuring Mission/Microwave Imager remote sensing data, J. Geophys. Res., 108(D2), 4038, doi:10.1029/2002JD002176, 2003. 